\title{
Combinatorial Mitigation Actions: A Case Study on European Union's Electricity Sector
}

\author{
Shijun Fu \\ Department of Logistic Engineering, Chongqing University of Arts and Sciences, Chongqing, China \\ Email address: \\ fsjphd@yahoo.com \\ To cite this article: \\ Shijun Fu. Combinatorial Mitigation Actions: A Case Study on European Union's Electricity Sector. International Journal of Economy, \\ Energy and Environment. Vol. 2, No. 5, 2017, pp. 77-86. doi: 10.11648/j.ijeee.20170205.11
}

Received: August 2, 2017; Accepted: August 10, 2017; Published: September 26, 2017

\begin{abstract}
Appropriate Greenhouse Gas (GHGs) mitigation action has become a promising concern because of its feasibility and sustainability. This article reviews mitigation approaches taken by European Union's electricity sector to promote appropriate reduction in large developing country. From an applicable and integrated aspect, it examines Emission Trading Scheme (EU ETS), carbon tax, Clean Development Mechanism, Joint Implementation, green electricity market, carbon capture and sequestration, and energy efficiency. Then the successful experiences and lessons on this case are identified. The former include: allow diverse approaches coexistence, establish ancillary service system, and make carbon market serve for electricity market. The latter contain that price fluctuates inappropriately, obligation is distorted, no banking for allowances operated in the first period, and part of abatement approaches conflict mutually. Based on these results, this article proposes a framework of combinatorial mitigation actions which is characterized as integral, collaborative and appropriate reduction. It is composed of: i) construct intensity-based carbon market; ii) make diverse approaches collaborative; iii) build synergy between mitigation approaches and electricity market; iv) enhance carbon management and auditing system; and v) reform aging power plants with low carbon technologies. Although numerous challenges lie ahead, this framework has the potential to reduce GHGs from electricity industry extensively and sustainably.
\end{abstract}

Keywords: Electricity Sector, EU ETS, Appropriate Mitigation, Combinatorial Mitigation Actions, Intensity-Based Carbon Market, Coordinated Regulation

\section{Introduction}

The influences of climate change include global public health pressures, increasing typhoon intensity and frequency, heat wave, flood damage, more contagious infections, security of foods and water, higher sea level, and social and economic destroys (Dhar et al., 2009). Before the first industry revolution, concentration of Greenhouse Gases (GHGs) in the atmosphere was about $280 \mathrm{ppm}$. According to Business As Usual (BAU) scenario, it will reach $550 \mathrm{ppm}$ and global mean temperature will increase $2-3^{\circ} \mathrm{C}$ in the next 50 years, which will induce $15-40 \%$ species extinguished and 200 million people migrated because of extreme climate. The causes and influences of climate change are characterized as globalization, long-run duration, and uncertainty. If combating climate change when those damages become reality, then the time is too late to convert this tendency (Stern, 2007).

Currently, GHGs concentration in the atmosphere is 358.66 ppm, among those caused by anthropogenic activities the electric power industry takes 24 percent, in absolute term, reaches $10.3 \quad \mathrm{GtCO}_{2} \mathrm{e}$ (Dincer \& Rosen, 1999). ${ }^{1}$ Besides electricity sector contributes to a large portion of anthropogenic GHGs, change in power sources structure is more flexible than convert energy supply in transport and other sectors (Convery et al., 2008). Both of them offer a huge abatement potential in this sector.

In June 2015, Chinese government announced that its GHGs emissions would be decreased by $60-65 \%$ per Gross Domestic Product (GDP) at 2030 year based on 2005 level. As the largest emission sector, currently Chinese electric power industry discharges $38.8 \%$ GHGs, and it still appears an increasing tendency. In Indian, energy sector takes $60.2 \%$ of its carbon emissions. From 1994 to 2007, India reduced carbon intensity by 30 percent. More ambitiously, it planed to reduce carbon intensity by a further $20-25$ percent between 2005 and $2020 .^{2}$ In the United States, electric power sector contributes over 33 percent of its total GHGs, so has been the 
focus of several state-sponsored mitigation initiatives (EPA, 2007). Obviously, it is an obligation for electricity sector to mitigate GHGs to prevent climate change reaching a dangerous level.

This paper is to review GHGs mitigation approaches taken by EU's electricity sector, and get policy implications for quick growth developing country, such as China and India, where fossil-fired power plants have discharged a large portion of GHGs, at the same time, addressing urgent poverty requires more and more electricity. Investigating from an applicable and integrated aspect, this article analyzes the successful experiences as well as flaws on mitigation approaches in EU's power sector, then, proposes a framework for reducing GHGs in this industry of large developing countries. The major contribution is that a set of combinatorial mitigation actions characterized as integral, collaborative and appropriate can motivate power plants to mitigate GHGs extensively and sustainably.

This paper is organized as five sections. The first section introduces the background. The second section does a case study on mitigation approaches taken by EU's power sector. The third section comments on the successful experiences and lessons on its abatement practice. The fourth section proposes a framework for GHGs reduction in electricity sector of large developing country and lastly, a brief conclusion is held in the final section.

\section{Approaches to Mitigation in Electricity Sector}

According to the Kyoto Protocol, EU countries committed to reduce $8 \% \mathrm{CO}_{2} \mathrm{e}$ emissions based on the 1990's level during 2008 to 2012 (Morthorst, 2001). At 2007, EU set a '20-20-20' climate and energy package for 2020 year, which includes that, GHGs emission reduces $20 \%$ in relation to the 1990 's figure, energy efficiency improves $20 \%$ based on the current conditions, and final energy consumption from renewable resources reaches 20\% (CEU, 2007). In October 2014, EU adopted its 2030 climate and energy framework, which comprises of three parts: at least $40 \%$ cut in GHGs emissions from 1990's level, 27\% improvement in energy efficiency, as well as $27 \%$ energy consumption from renewable sources. It also set a long-run mitigation goal that requires $60 \%$ and $80 \%$ reduction in terms of the 1990's level at 2040 and 2050 year, respectively. ${ }^{3}$ In order to reduce GHGs discharged from electric power sector, EU has taken seven main approaches: Emission Trading Scheme (ETS), Clean Development Mechanism (CDM), Joint Implementation (JI), carbon taxes, green electricity market (renewable energy), Carbon Capture and Sequestration (CCS) technology, and energy efficiency policies.

\subsection{EU ETS}

\subsubsection{EU ETS Review}

In economics term, creating emission rights and allowing them to be traded among market participants can reduce carbon emissions in a cost-effective way. Furthermore, it is more flexible to adapt to changes in economy development.
EU Emission Trading Scheme (EU ETS) market design is righteously based on this common recognition: Creating a price for carbon emission can realize global GHGs deep reduction in the most cost-effective way, therefore, may effectively prohibit climate change reaching a dangerous degree (EC, 2008).

EU ETS is divided into four trade periods: 2005-2007, 2008-2012, 2013-2020, and 2021-2030. This market system is comprised of four interacted aspects: carbon trade, carbon finance, carbon management, and carbon auditing, where carbon trade adopts a cap-and-trade way. In October 2001, EU released a directive opinion on trading carbon emission rights, and European Parliament passed it in 2003. At January 2005 EU ETS began operation, it covered around 45\% EU emissions discharged by 11,500 companies, and the turnover was $€ 14.6$ billion in 2006 year (Nielson, 2008). In 2010, EU allowances contributed to $84 \%$ of the value of total global carbon market. Just in 2012 year, this market traded 7.9 billion allowances and was worth of $€ 56$ billion. Up to now, the geographic scope of EU ETS has covered EU-28 Member States, Iceland, Liechtenstein, and Norway. It includes seven kinds of GHGs emissions from installations such as power stations, combustion plants, oil refineries and iron and steel works, as well as factories making cement, glass, lime, bricks, ceramics, pulp, paper and board. From 2016, aviation sector also has been introduced into EU ETS system. Since it began operation, the turnover is increasing, geographic scope is extending, and covered sector is expanding. All these signals show that EU ETS market is growing quickly. It can be seen in Figure 1.

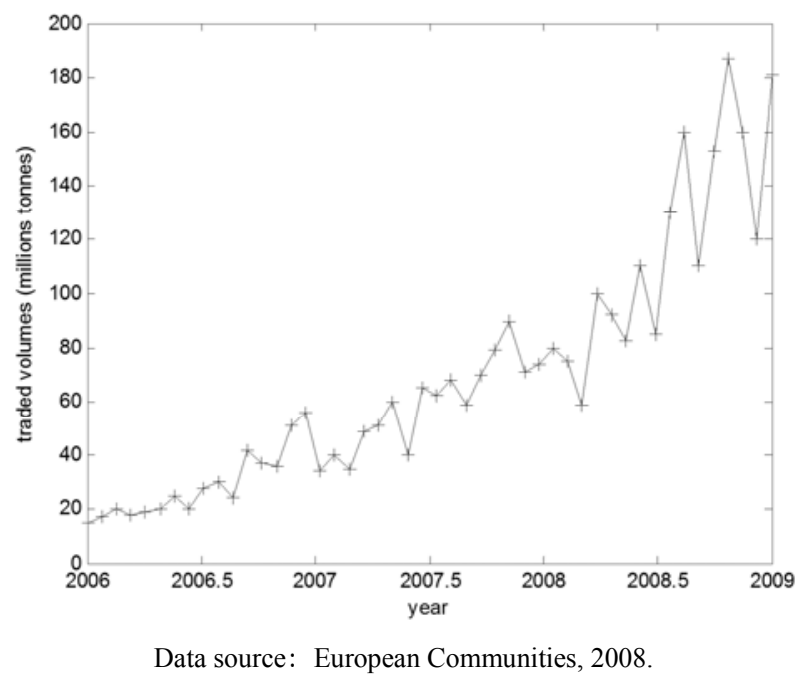

Figure 1. EU ETS market turnover from January 2006 to December 2008.

\subsubsection{Initial Allowances Allocation}

Different method of initial allowances allocation may induce different cost when power plants implement mitigation obligation, therefore, influence their decision-making in competitive electricity market (Betz \& Sato, 2006). In theory, there are three ways for allocating initial allowances: grandfathering, auctioning, and fixed price. During EU ETS first pilot period, 95 percent of allowances are allocated by grandfathering (free of charge) and the spare by auctioning. 
During its second period, free allocation is decreased and at least 10 percent are allocated by auctioning. Furthermore, this portion will reach 57 percent at third trading period. Specifically, from 2013 to 2020 all allowances in power sector will be distributed in auction, except some eight member states needing to modernize and diversify their power sources, since EU ETS practices have shown that even allocated free of charge, power plants can successfully transfer carbon price to final consumers (EC, 2008).

Concerning allowances cap, during the second period EU scheduled to reduce its carbon emissions from 2,298.5 $\mathrm{MtCO}_{2} \mathrm{e}$ to $2,086.5 \mathrm{MtCO}_{2} \mathrm{e}$, where the new entrant countries and sectors were also included. The 2013 cap for emissions was 2,084.3 $\mathrm{MtCO}_{2} \mathrm{e}$. During 2013-2020, this cap will decrease yearly by a linear reduction factor of $1.74 \%$ of mean quantity of allowances allocated annually in the second phase. The European Commission adopted a legislative proposal in July 2015 to revise EU ETS from 2021-2030, which was the milestone in putting EU on the track to reduce GHGs emissions by at least $40 \%$ by 2030 and as part of intended contribution to the Paris Agreement. Therefore, its overall number of allowances will decrease further at a rate of $2.2 \%$ from the beginning of EU ETS fourth period.

\subsubsection{Features on EU ETS}

EU ETS is the earliest and largest multi-country carbon market at enterprise level. Its market design was taken into consideration by Australia, Norway, Switzerland, North American Regional Greenhouse Gas Initiative (RGGI), India, South Korea, and China. According to the work by Klepper and Peterson (2006), Ellerman and Joskow (2008), Nielson (2008) as well as our investigation, this article summarizes the features on EU ETS as follow:

Type of reduction goal: Absolute quantity control (i.e., $\mathrm{X}$ $\mathrm{tCO}_{2} \mathrm{e}$ ). One share of European Union Allowances (EUAs) allows its holder to emit one $\mathrm{tCO}_{2} \mathrm{e}$ and an explicit valid period is specified.

Default emission penalty: $€ 40$ per extra emitted $\mathrm{tCO}_{2}$ e was charged in the first pilot stage, and this penalty was increased to $€ 100$ in the second stage.

New entrants: EU will consider the carbon quota requirements for new entrants, but the detail plans such as how many quotas are provided and how to distribute them, are determined by each Member State respectively. From 2013 onwards, 300 million allowances was set aside in the New Entrants Reserve (NER) to fund the distribution of innovative renewable energy technology and CCS, known as the NER 300 programme.

Enterprise close: EU Member States may determine whether or not carbon quotas are submitted or held as an asset when enterprise is closed. Correspondingly, transferring these quotas from one company to another needs to be carefully considered by each Member State.

GHGs traded: Only $\mathrm{CO}_{2}$ was allowed during the first pilot period, $\mathrm{N}_{2} \mathrm{O}$ was introduced from the start of second trade period, and seven kinds of GHGs were included from 2013.

Reduction style (i.e., in a mandatory or voluntary way): Mandatory manner. From beginning of the third period, a single EU-wide cap on emissions has replaced the previous national caps.

Market participants: Emitters.

Offset mechanisms: Emitters may apply CDM and JI approaches specified by the Kyoto Protocol to counteract their obligation. Concretely, in the first period only CDM except reforestation and afforestation project was allowed, thereafter, JI project was also allowed.

Allowances banking: Except for a few member states, no banking is allowed in the first period. But from the second period, EUAs can be banked for the next trade period.

Sectors covered: In the first pilot period, EU ETS covered electricity, refinery, building materials (glass, lime, cement, brick, tile and ceramic production), iron and steel, and pulp and paper. In the second stage, it extended to chemical industry, foods and drink, aluminum, minerals exploit and services. From 2016, it was further extended to aviation.

Under EU ETS system, carbon price is mainly affected by: allowances cap determined in terms of BAU scenario, external carbon credit supply based on the CDM and JI programme, fossil fuel price, weather conditions (temperature, rainfall, cloud and mist etc.), regulatory rules such as National Allocation Plans (NAPs), and policy uncertainty (Alberola et al., 2009a). Holding carbon price within an appropriate range is vital for maintaining market stable as well as stimulating power plants to invest in low-carbon technology and renewable energy. However, it is always difficult to be realized. Since EU ETS began to work at January 2005, carbon price tripled in the first six months, and collapsed by half in a one-week period in 2006 because of EU releasing new allocation plan, then declined to zero over the next twelve months. Figure 2 reveals that from November 2005 to November 2008, carbon price fluctuated between $€ 12$ and $€ 34$. If taking the price when EUAs quitting market into consideration, this gap is much larger. At later, the huge surplus emission allowances accumulated since 2009 also damaged carbon price. Such an unexpected price and implied volatility raise questions about the feasibility of this trade system to provide sustainable incentives to power plants (Ellerman \& Joskow, 2008).

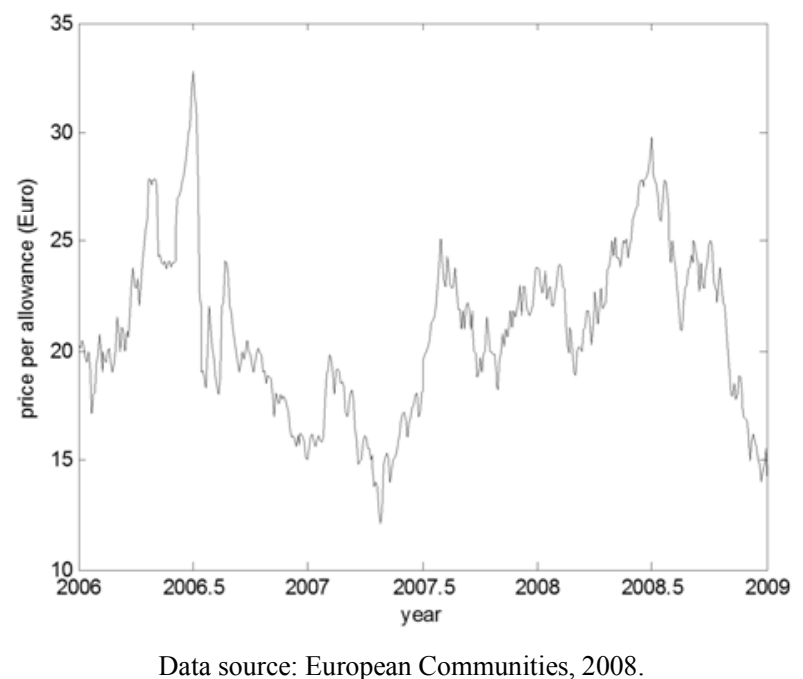

Figure 2. EU ETS market price from January 2006 to December 2008. 


\subsubsection{Other Related ETS}

More and more EU countries start building their domestic carbon markets and linking them to EU ETS system by so-called linking directive (Sterk, 2005, p. 25).

UK ETS: ${ }^{4}$ The UK was one of the pioneer countries that built domestic ETS market. It aimed at controlling total emission quantity, and market participants included those who would be regulated by ETS (i.e., both GHGs emitters and users). UK ETS ran in parallel to a tax on energy use, the Climate Change Levy introduced in April 2001. Companies could get a discount on the tax if they elected to make reductions through the trade scheme. UK ETS traded all the six GHGs specified in the Kyoto Protocol and covered all sorts of industry and energy departments. Its first trading period ran from 2002 to 2006. For default emission penalty, this mechanism specified that 30 pound per extra emitted $\mathrm{CO}_{2} \mathrm{e}$ was charged, as well as correspondingly decreasing allowances quantity and subsidy in the coming year. UK ETS did not allow offset through CDM and JI project, however, it allowed carbon allowances to be banked for the next trade period. The UK aggressive and ambitious ETS enabled London standing on the center of the emerging carbon markets. According to the World Bank, 59 percent of trade in global carbon market was organized through London (Capoor \& Ambrosi, 2008).

Norway ETS: ${ }^{5}$ Operated from January 2005, its market design was similar to the first phase of EU ETS. Since carbon tax and carbon market coexist, Norway ETS is only mandatory for enterprises that do not apply to carbon tax. In comparison to 45 percent of emissions in EU is covered by EU ETS, only 10 percent of emissions in Norway is included in this market. The Norway ETS allows power plants to use EU allowances and $\mathrm{CDM}$ credits for compliance in the commitment period. It also sets a default penalty at $€ 40$ per extra $\mathrm{tCO}_{2} \mathrm{e}$, the same as EU ETS in the first stage. In addition, under Norway ETS system allowances can be banked for the next period.

Switzerland ETS: Switzerland set domestic ETS at 2008, and its first trading phase lasted from 2008 to 2012 . Switzerland ETS aims at controlling total emission quantity and participants are restricted within emitters (they have a right to choose whether or not to participate the trade system).
The traded GHGs of Switzerland ETS is only $\mathrm{CO}_{2}$ and covered sectors are related to lime, electricity, aluminum, pulp and paper, iron and steel, glass, ceramic, and other industries. Switzerland ETS still sets a rigorous default penalty that includes levying carbon tax as well as charging interests for per extra $\mathrm{tCO}_{2}$. This mechanism is more flexible than EU ETS, since it not only allows emission rights to be banked, but also adopts offset through CDM and JI project.

Denmark carbon quota: Denmark sets a carbon quota for every power plant and these quotas can be traded among market participants. If power plant emitted GHGs surpass allowances submitted, the spare will be fined around $€ 5.4$ per extra $\mathrm{tCO}_{2} \mathrm{e}$ during 2001 and 2003.

\subsection{CDM and JI Mechanism}

Under the previous EU ETS system, CDM and JI programme act as an important role. They are carbon offset mechanisms specified by the Kyoto Protocol which ensure that, enterprises committed concrete obligations in developed countries invest in mitigation project in the third-party countries to offset their compliance. The CDM project is suitable for developing countries and generated carbon credit is called Certified Emissions Reductions (CERs). The JI project is suitable for industrialized countries and countries where economy is at their transition stage, correspondingly, generated carbon credit is called Emissions Reduction Units (ERUs). The traded unit of these mechanisms is equal to the EUAs.

In economic theory, the international carbon trade through CDM and JI mechanisms is based on the fact: the marginal abatement cost is different among developed and developing countries. As depicted in Figure 3, Stankeviciute et al. (2008) studied the marginal abatement cost in some countries/regions at year 2010 and 2020 and found that, different country/region has different marginal abatement cost, even in the same country, the cost is still diverse at different period. This provides a theoretic foundation for carbon spot market and derivative market, such as carbon future, carbon option, and carbon forward market, etc.

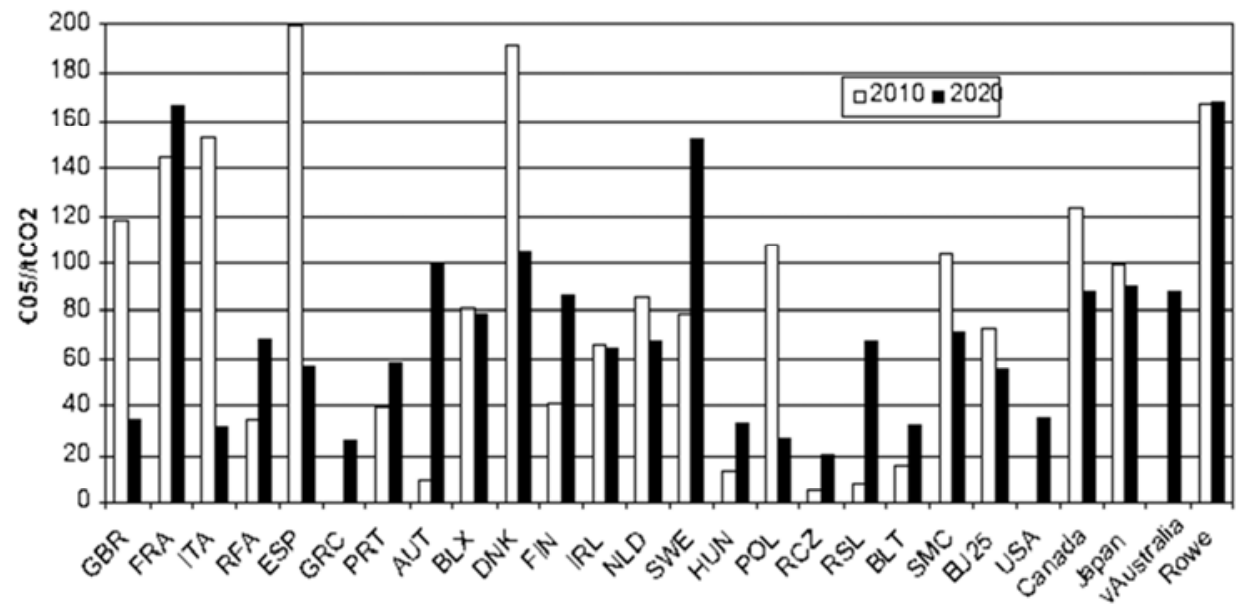

source: Stankeviciute et al., 2008.

Figure 3. Marginal abatement cost of selected countries/regions at 2010 and 2020 year. 
Partly as economic crisis and partly as CDM and JI operation, a considerable surplus of emission rights has been produced since 2009. The surplus accumulated to more than 2.1 billion in 2013, which led to the European Commission addressing this problem through both short- and long-term policies, such as 'back-loading' auctions of 900 million allowances during 2014-2016, a proposal of structural reformation of EU ETS in July 2015, etc. As a universal, legally binding climate deal, the Paris Agreement proposes a new market mechanism to replace CDM and JI after 2020. That means, it provides a robust and ambitious basis for the use of international markets and, enhances international targets, transparency and accountability of the UNFCCC parties.

\subsection{Carbon Tax}

In an economic perspective, carbon tax is a type of Pigovian tax levied on released GHGs or the carbon content of fuels. As a governmental regulatory approach, carbon tax can promote GHGs reduction directly. Voorspools and D'haeseleer (2006) investigated mitigation effect in EU Member States and revealed that, levying only $€ 10$ on per metric $\mathrm{tCO}_{2} \mathrm{e}$ has induced huge extra burden to fossil-fired power plants. In the first phrase, EU ETS levied $€ 40$ on per default $\mathrm{tCO}_{2} \mathrm{e}$. In 2010 , the European Commission considered to introduce a pan-European tax on emission permits traded under the EU ETS scheme, in which it would be calculated according to carbon content rather than GHGs released. This plan would levy firms a minimum carbon tax around $€ 4$ to $€ 30$ on per metric $\mathrm{tCO}_{2} \mathrm{e}$. In Norway, Switzerland, Ireland, UK, Germany and Denmark, there also have carbon tax and ETS coexistence.

In the field of applying carbon tax to promote mitigation in power sector, part of EU Member States has designed a feed-in tariffs approach (Verhaegen et al., 2009). It requires grid operator prior dispatching electricity produced by Renewable Energy Sources (RES) at the lowest cost, then, government provides a subsidy for RES power plants in a feed-in tariff way. Obviously, feed-in tariff is an effective approach to motivate EU electricity production transferring to renewable energy.

\subsection{Green Electricity Market}

In order to realize obligation regulated by the Kyoto Protocol, EU Member States have taken many approaches in power sector, such as EU ETS, domestic ETS, CDM and JI, and carbon tax. Besides these, Tradable Green Certificates (TGCs) is another way to reduce emission by supporting electricity production from renewable energy.

As a cost-effective approach, TGCs has strong incentives to transfer electricity production to renewable energy. It requires consumers purchasing a fixed proportion of electricity generated by renewable energy, thus, they need submit equivalent TGCs to market organizer every year. These TGCs can be traded among market participants during their valid period, correspondingly, governments will pay a subsidy on investment in RES electricity production at supply side (Verhaegen et al., 2009).

Because of political reasons, TGCs in EU Member States are very different in legal base, definition, market condition, and coexistence with RES regulation (Nielsen \& Jeppesen, 2003). In legal base aspect, TGCs in different state has different proportion of new energy consumption. For instance, this weight was $10 \%$ in Britain but $5 \%$ in Netherlands at 2010 year. In definition aspect, TGCs traded in Britain and Denmark does not include large-scale hydropower station, meanwhile, TGCs in Netherlands and German does not contain power station fueled by wasted materials. Even in the same country, TGCs definition is still differential: in Belgium, at least four types of TGCs coexist; in Flanders and Brussels, power plant with capacity above $10 \mathrm{MW}$ may be valid for TGCs subsidy, while in Walloon only power plant higher than $20 \mathrm{MW}$ has this right. In market condition aspect, Denmark establishes an independent fund to manage TGCs market stability, in contrast, Italy requires TGCs Issue Bureau (IB) to be responsible for market stable by controlling initial allowances. Concerning coexistence with RES regulation, different country implements different price subsidy policy, furthermore, level of fixed feed-in tariff subsidy and degree of new energy subsidy are also various in each state.

Obviously, the above diversity has damped TGCs development, therefore, coordinating and establishing a uniform TGCs market across EU Member States become a tendency that promotes electricity production transferring to renewable energy (Verhaegen et al., 2009).

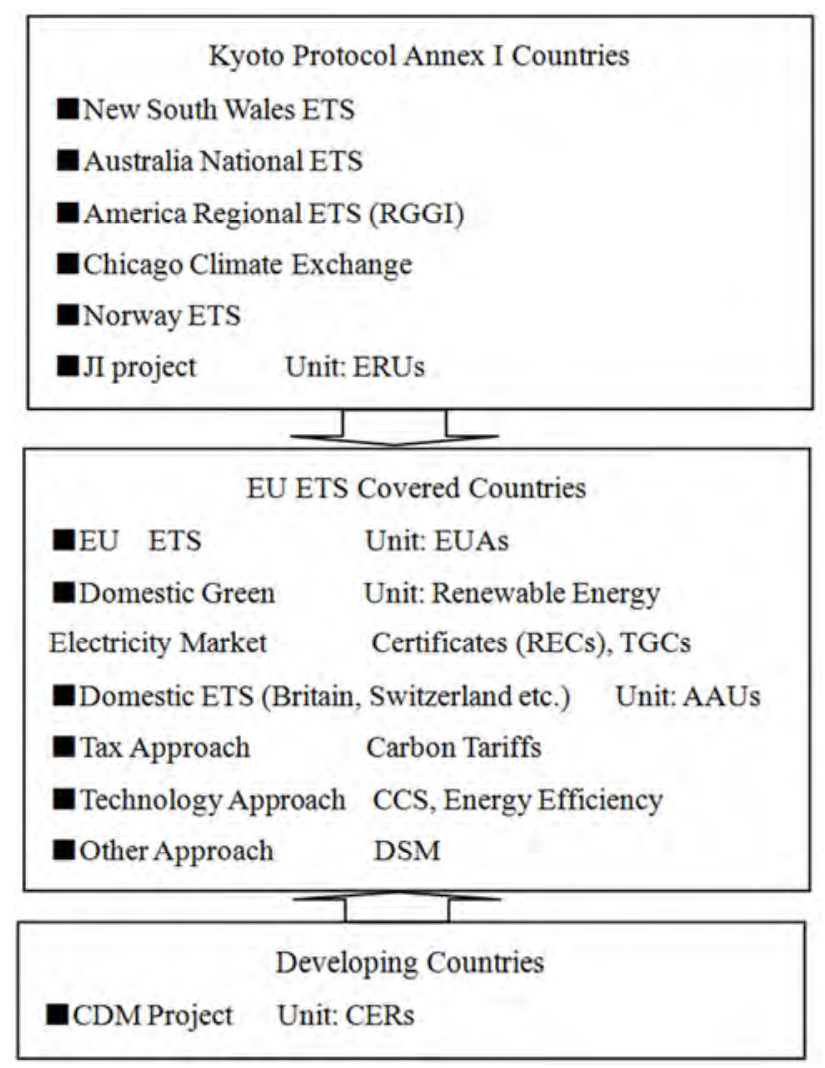

Figure 4. Carbon abatement approaches for EU power sector. 
Morthorst (2001) made an experimental research on mutual actions between TGCs market and the Tradable Carbon Emission Permits (TCEPs) market through carefully examining three scenarios: only TGCs market, TGCs and TCEPs with grandfathering and, TGCs and TCEPs with auctioning. This work suggested that, the later provides power plants stronger incentives to reduce GHGs and adopt renewable energy technology. So it is an effective policy to offer diverse approaches and allocate allowances by auctioning.

Except for the above mentioned approaches, applying Carbon Capture and Sequestration (CCS), promoting advanced power generation technology to improve energy efficiency, and enhancing electricity Demand Side Management (DSM) are also effective abatement approaches. Figure 4 summarizes the main approaches for carbon mitigation in EU power sector.

\section{What does Mitigation in EU Electricity Sector Imply}

\subsection{Successful Experiences}

As the largest and earliest GHGs trade region, EU has accumulated many successful experiences on mitigation in electricity sector. Based on the survey in section 2, this part discusses and summarizes them as follow.

Experience 1: Allow diverse mitigation approaches coexistence-In order to reduce GHGs from electric power industry, EU applies many intergovernmental-, regional-, and domestic-approaches based on marketization and governmental regulation, such as EU ETS, domestic ETS, CDM and JI, carbon tax, green electricity market, CCS etc. It reveals an important signal: regulator and market organizer should jointly create many mitigation approaches in terms of marketization and economic regulation. Since emission permit has become a necessity for fossil-fired power plants (PointCarbon, 2004), coexistence for diverse approaches can effectively increase price elasticity, therefore, reduce carbon risk and make mitigation actions sustainable (Eriksen, et al., 2011).

Experience 2: Establish ancillary service system for carbon trade-EU practice displays that, getting each participant's emission data before market exchange is a necessary condition for effective carbon market with information transparency (Nielson, 2008). National Allocation Plans, EUAs inventory, annual report regulation as well as single EU-wide cap are well designed and implemented in EU ETS system. Thus, reinforcing carbon management and auditing by establishing measurable, reportable, and verifiable ancillary service system (IPCC, 2007) is a precondition for carbon market reliable and sustainable operation.

Experience 3: Make carbon market serve for electricity market - There have extensive literatures on EU ETS, most of them support that carbon market has improved resources allocation efficiency in electricity market (Delarue et al., 2007; Newcomer et al., 2008). Kockar et al. (2009) explored the changes in cost burden and competitive ability in electricity market after introducing EU ETS. They build a cost minimization model for power system, which concerns actual restrictions such as load balance, named power, start- and off-time, reserved capacity, fuel consumption characteristics, and carbon allowances cap. They suggest that EU ETS can improve competitive ability of power plants with low carbon intensity, but this effect is vanished when none reaches its capacity limit.

Borchiellini et al. (2000) also argued that under EU ETS system, carbon intensity has an important effect on power plant's marginal cost: Carbon price may increase operational cost, therefore, offset part of revenue brought by emission abatement. They emphasize that carbon market can change the order of dispatched power plants: Power plants with higher carbon intensity are often at the fringe of last-in-line dispatched position.

Since electricity production from new energy sources and RES has lower carbon intensity and, scaled fossil-fired power plants own emission advantages over small ones, thus, introducing carbon market may well improve resources allocation efficiency in electricity market.

\subsection{Lessons to Be Alerted}

Although EU power sector has achieved great success in carbon mitigation, there still exist some flaws inherent in mechanism design. In terms of the case study in section 2, this part lists them as follow:

Lesson 1: Price is low, unexpected and transferred-As mentioned in section 2, carbon price has an immediate relationship with energy price, high temperature industry, weather conditions, and trade mechanism (Alerola et al., 2009b). Some literatures suggested that during the first pilot period of EU ETS, price fluctuating unexpectedly may be attributed to market design (Tideman \& Plassmann, 2007; Nielson, 2008). Some literatures predicted EU ETS price in terms of National Allocation Plans (NAPs) and revealed that, supply abundance and no banking for allowances are major factors responsible for price decreasing (Klepper \& Peterson, 2006; Ellerman \& Joskow, 2008). Carbon price fluctuating unexpectedly brings huge risk to fossil-fired power plants, therefore, can not effectively motivate them investing in abatement Research and Development (R\&D), such as CCS, combustion technique, and energy efficiency. Obviously, market regulator can ensure price at a suitable and stable level through maintaining carbon allowances scarcity appropriately. Note that, auctioning has a benefit to keep allowances scarcity (Alberola et al., 2009b), thus, it is important for market designer to distribute initial allowances by auctioning.

Under carbon trade mechanism, the degree of carbon price transferred to final consumers is crucial to motivate power plants reducing emission. By applying dominant-firm competitive model, Liliya and Gulli (2008) measured the effect of electricity market structure on the proportion of carbon price transferred. They find that the incremental electricity price may be higher or lower than carbon price; which is determined by market concentration, available capacity, power sources structure, load demand, and peak level. According to an experimental research held by 
Bonacina and Gulli (2007), in perfect competition market carbon price is totally transferred to electricity price, however, this percentage is decreased with increasing market concentration, and shortage of reserved capacity. Since EU ETS started in place, coal-fired power plants has increased their cost around $€ 10 / \mathrm{MWh}$, meanwhile, final consumers also bore the same burden during 2005 and 2007. In Germany the proportion of carbon price transferred is about $100 \%$, and in north Europe this ratio ranges from $75 \%$ to $95 \%$ (Atukia et al., 2006; Sijm et al., 2006). The phenomenon of high transferred proportion can not well motivate power plants to adopt CCS technology, and invest in long-run mitigation.

Lesson 2: Mitigation obligation is distorted-Anger (2008) studied the interaction between EU ETS, non-energy-intensity industry, and over EU-scope carbon trade during the post Kyoto Protocol period. This research finds that, since non-energy-intensity industry is excluded from EU ETS system, and obligation is restricted within energy-intensity industry, hence, allowances allocation free of charge induces obligation being shifted to countries or enterprises beyond the EU ETS scope. Both Anger (2008) and Alberola et al. (2009b) suggested that establishing a collaborative international carbon market: beyond EU ETS, including non-energy-intensity sector and, allocating allowances by auction, may reconcile this distortion. Fortunately, this suggestion has been adopted by the Paris Agreement in December 2015.

Lesson 3: No banking for allowances-Allowances banking may better stimulate power plants to reduce emission, therefore, make mitigation actions appropriate and sustainable. During the EU ETS first pilot period, carbon price decreased sharply (drop from above $€ 30 / \mathrm{tCO}_{2}$ in April 2006 to below $€$ $1 / \mathrm{tCO}_{2}$ in February 2007) when EU released new allocation plan in April 2006 (Kockar et al., 2009). It has a direct relationship to market design that does not allow allowances to be banked for the second phase. Governed by no banking rule, power plants are reluctant to invest in CCS technology, combustion technique, energy efficiency, and related R\&D through balancing long-run and short-run benefits. As mentioned in section 2.1.3, allowances could be banked for next trade period since the EU ETS second stage.

Lesson 4: Part of mitigation approaches conflict each other-As described in section 2, EU member states have taken diverse approaches to mitigate GHGs from electricity sector. Ellis and Tirpak (2006) argued that there coexist many different carbon markets, consequently, it is difficult to make them work collaboratively in key aspects, such as objective, price regulation, non-obligation allowances supply, banking, offset and credits, and initiate allocation methods. The synergy effect is damped because different carbon markets conflict each other (Sorrell \& Sijm, 2003).

Furthermore, overemphasizing liquidity among different carbon markets may destroy their mitigation function. Ellis and Tirpak (2006) sorted all mitigation market as two types: single linkage and double linkages - the former means emission permits trading in market A may apply to market B, but the inverse is forbidden, in contrast, the later means permits in both markets are applicable each other. This research shows that double linkages can enhance market liquidity, but, will offset mitigation effect. Gillenwater (2008) also suggested that, although consumers purchase Renewable Energy Certificates (RECs) in voluntary green electricity market may generate subsidies for power plant with renewable energy, however, RECs trade among them can not bring incremental abatement effect.

\section{Policy Implication: Combinatorial Mitigation Actions for Electricity Sector}

As the largest and quick growth developing country, both India and China have discharged considerable GHGs from electric power industry, furthermore, addressing chronic poverty needs more and more electricity. Gradually, establishing diverse approaches that are compatible with electricity market and international carbon trade system, not only benefits power industry sustainable development, but also acts as responsible countries in dealing with climate change. Concerning experiences and lessons on EU power sector as well as concrete national situations, large developing country such as India and China, may consider the following combinatorial mitigation actions to reduce GHGs from this industry.

\subsection{Establish Regional Intensity-Based Carbon Market, and Gradually Transfer to a Uniform Market}

As a global public good, controlling GHGs need obey "the emitters pay" principle, which implies that policy maker needs to make emitter's external cost internalized. And establishing emission intensity-based carbon market may satisfy this requirement (Paterson, 2012). Since controlling emission is related to all sorts of sectors in a national wide scope, different sector even different hierarchy in the same sector has special mitigation feature. For example, in China, six regional grids own diversified power sources structure, and their coal property is also heterogeneous, furthermore, both northeast grid and middle grid own large part of old technique generators. All these factors bring carbon intensity gap between 0.514 and $1.246 \mathrm{tCO}_{2} \mathrm{e}$ per megawatt hour among regional grids. When concerning at power plant level, this gap is bigger than the above (Fu \& Ren, 2011). The same is true in Indian electricity sector. In order to make mitigation actions appropriate and sustainable, government may consider stepwise establishing regional intensity-based carbon market. When regional markets develop matured, it may gradually transfer them into a national/international uniform market.

Meanwhile, government may stepwise develop related derivative markets, such as carbon futures, carbon options, and carbon forward contracts, because their price discovery function can flat price over-fluctuation in spot market. The goal of emission trade is to reach environmental objective at the most economy way (Nielsen \& Jeppesen, 2003). Government may provide power plants long-run abatement version to motivate them investing in clean electricity technology, and restrict taking allowances allocation as an 
instrument to achieve other energy policy objective (Paterson, 2012). In initial allocation market, regulator may set appropriate rules to ensure auction not triggering unexpectedly high electricity price. In competitive market, environment regulator and electricity regulator need work collaboratively to supervise that, transferred carbon price aims at promoting clean electricity production, CCS technology, $\mathrm{R} \& \mathrm{D}$, and electricity demand-side responses.

\subsection{Design Diverse Mitigation Approaches and Make Them Work Collaboratively}

To reduce GHGs from power sector, EU Member States introduced many approaches at different hierarchy. Under the joint work of these approaches, price elasticity is well increased, therefore, carbon risk of electricity production is decreased considerably (Point Carbon, 2004). Concerning EU mitigation actions in power sector, India and China may convert to new energy and renewable energy generation, improve energy efficiency, and enhance electricity demand-side response (Chen et al., 2005). Based on these grass-root works, government may gradually set carbon trade, carbon tax, TGCs market, research and development for CCS investment, at the mean time, promote them work collaboratively to improve integral effect.

In addition, although most consumers in green electricity market do not care about the real environmental benefits brought by their purchasing behavior, they still prefer to procure green electricity (Menges, 2003; Bird et al., 2007; Brody et al., 2012; Goett \& Hudson, 2000). Hence, fostering voluntary green electricity market is also another cost-effective approach to stimulate GHGs reduction from fossil-fired power industry.

\subsection{Build Synergy Between Mitigation Approaches and Electricity Market}

EU ETS practice has proven that the two processes of reforming electricity market and mitigating GHGs emissions can be realized coordinately. Perkins (2005) also provided the fact that in large developing country, power industry reformation by encouraging Independent Power Producers (IPPs) entering market exchange may successfully decrease average carbon intensity.

According to the Electricity Market Capacity Building Planning (EMCBP), ${ }^{6}$ Chinese middle- and long-run objective is to establish six regional electricity markets, then, gradually transfer to a uniform national electricity market. Therefore, when government plans domestic carbon markets, it is strategic to make them compatible with electricity market: in aspects of geographical scope, trade period, and regulatory rules. Obviously, the same also applies to Indian power industry, where the situation is very similar to China.

\subsection{Improve Ancillary Service System for Carbon Management and Auditing}

EU mitigation experiences reveal that, establishing measurable, reportable, and verifiable ancillary service system is a precondition for carbon markets reliable and sustainable operation. To successfully mitigate GHGs from power industry, government also need stepwise build carbon measure system, carbon report system, and carbon auditing system.

According to the 2006 IPCC Guidelines for National Greenhouse Gas Inventories, China has compiled the Guidelines for Provincial Level Greenhouse Gas Inventories. India also released the Greenhouse Gas Inventory at a state level. However, there have numerous works on capacity building to be enhanced for appropriate and sustainable mitigation in electricity sector, such as carbon finance, carbon management, carbon auditing, and measurement on emission intensity for each power plant (Chen et al., 2005; Fu \& Ren, 2011).

\subsection{Set Technique Reform on Aging Fossil-Fired Plants to Modernize Electricity Sector}

SÖderholm and StrÖmberg (2003) held that in the middleand long-term, most EU power plants are more willing to reform conventional techniques to respond to EU ETS market, rather than CDM or other approaches because of cost saving. A report by MIT (2009) revealed that, comparing with electricity production by new energy and renewable energy, fossil-fired electricity production has obvious cost advantages. Except carbon price high enough, it is very difficult to be counteracted.

Another research by Perkins (2005) suggested that, retrofit and upgrade old fossil-fired plants with advanced generation technique and CCS technique is a cost-effective, appropriate, and sustainable mitigation approach. Generally, install CCS facilities, improve heat efficiency, optimize power sources structure, and mix combustion with fossil fuel and low carbon fuel, all these approaches are feasible to effectively promote low carbon intensity for power plants.

\section{Conclusions and Recommendations}

Combating climate change offers a rigorous challenge to power industry worldwide, especially for large developing country such as India and China, where electricity sector has emitted considerable GHGs while addressing urgent poverty requires electricity grows quickly.

This paper investigates mitigation approaches taken by EU power sector to promote appropriate and sustainable mitigation in India and China. From an applicable and integrated aspect, this article carefully examines EU ETS, carbon tax, CDM and JI, green electricity market, renewable energy, and energy efficiency policies. In lieu of these surveys, valuable experiences on mitigation in power sector are offered, which include,

i) allow diverse mitigation approaches coexistence to offset carbon risk;

ii) establish ancillary service system for carbon trade; and

iii) make carbon market serve for electricity market.

On the other hand, this article also summarizes the shortcomings on GHGs abatement in EU power sector, which contain,

i) price fluctuates unexpectedly and is transferred to final 
consumers almost completely;

ii) mitigation obligation is distorted because of allowances free allocation;

iii) no banking regulatory for allowances operated in the first period; and

iv) different abatement approaches conflict each other.

Based on these results, this paper proposes a framework of combinatorial mitigation actions for large developing country, especially for India and China. It is composed by five interactive aspects:

i) establish regional intensity-based carbon markets, then, gradually transfer to a national/international uniform market;

ii) design diverse mitigation approaches and make them work collaboratively;

iii) build synergy between mitigation approaches and electricity market;

iv) improve ancillary service system for carbon management and auditing; and

v) set technique reform on aging fossil-fired plants to modernize power industry.

Although numerous challenges lie ahead, this article suggests that this framework can bring a feasible, sustainable and appropriate mitigation action in power industry of large developing country. For further work, it is necessary to precisely investigate emission intensity for fossil-fired power plants to make mitigation action more effective.

\section{Acknowledgements}

This paper is supported by Natural Science Foundation Project of CQ CSTC (No. cstc2012jjA20013) and Chongqing University of Arts and Sciences Projects (No. R2012JG04; No.130306). The author is solely responsible for any errors or omissions.

\section{Notes}

1. Where the first three largest sources are $\mathrm{EU} 1.6 \mathrm{GtCO}_{2} \mathrm{e}$, North America $3 \mathrm{GtCO}_{2} \mathrm{e}$, and China $1.7 \mathrm{GtCO}_{2} \mathrm{e}$ respectively.

2. See http://www.worldwatch.org/node/6449.

3. See Council of the European Union, 2007. http://www.ec.europa.eu/clima/news/index_en.htm.

4. For more details, see the place of the UK emissions trading scheme in the UK climate change programme. http://www.ucl.ac.uk/uctpa15/uk_ets_info.htm.

5. See the Norwegian emissions trading system. Royal Norwegian Ministry of Environment. http://www.icao.int/Meetings/EnvironmentalWorkshops/Doc uments/WACM-2008/3Svarstad.pdf.

6. Offered by Chinese State Electricity Regulatory Committee (SERC).

\section{References}

[1] Alberola, E., Chevallier, J., and Cheze, B. (2009a). The EU emissions trading scheme: disentangling the effects of industrial production and $\mathrm{CO}_{2}$ emissions on carbon prices. International Economics 9(2): pp 116-131.
[2] Alberola, E., Chevallier, J., and Cheze, B. (2009b). Emissions compliances and carbon prices under the EU ETS: A country specific analysis of industrial sectors. Journal of Policy Modeling 31(3): pp 446-462.

[3] Anger, N. (2008). Emissions trading beyond Europe: Linking schemes in a post-Kyoto world. Energy Economics 30(4): pp 2028-2049.

[4] Atukia, H., Malkonen, V., and Perrels, A. (2006). Impacts of the European emission trade system on Finnish wholesale electricity prices. VATT Working Papers, pp 405-417.

[5] Betz, R., and Sato, M. (2006). Emissions trading: lessons learnt from the 1st phase of the EU ETS and prospects for the 2nd phase. Climate Policy 34(6): pp 351-359.

[6] Bird, L., Holt, E., and Carroll, G. (2007). Implications of carbon regulation for green power markets. National Renewable Energy Laboratory, Golden, CO.

[7] Bonacina, M., and Gulli, F. (2007). Electricity pricing under carbon emissions trading: a dominant firm with competitive fringe model. Energy Policy 35(9): pp 4200-4220.

[8] Borchiellini, R., Massardo, A., and Santarelli, M. (2000). Analytical procedure for carbon tax evaluation. Energy Conversion and Management 41(5): pp 1509-1531.

[9] Brody, S., Grover, H., and Vedlitz, A. (2012). Examining willingness of American to alter behavior to mitigate climate change. Climate Policy 12(2):pp 1-22.

[10] Capoor, K., and Ambrosi, P. (2008). State and trends of the carbon market. World Bank, Washington, DC.

[11] CEU (Council of the European Union). (2007). Presidency conclusions, Brussels.

[12] Chen, H. G., Hu, H. G., and Pan, J. H. (2005). Low carbon development: challenges for China as a rapidly industrializing developing country. China and World Economy 13(2): pp 64-77.

[13] Convery, F., Ellerman, D., and Perthuis, C. D. (2008). The European carbon market in action: Lessons from the first trading period. Interim Report.

[14] Delarue, E., Lamberts, H., and D'haeseleer, W. (2007). Simulating green house gas allowance cost and GHG emission reduction in western Europe. Energy 32(3): pp 1299-1309.

[15] Dhar, Y., Divya, B., and Macmillan, N. (2009). Carbon pricing in New Zealand: Implications for public health. New Zealand Medicine Journal 122(1290): pp 105-115.

[16] Dincer, I., and Rosen, M. A. (1999). Energy, environment and sustainable development. Applied Energy 64(3): pp 427-440.

[17] EC (European Communities). (2008). EU action against climate change. Luxembourg: Office for Official Publications of the European Communities.

[18] Ellerman, A. D., and Joskow, P. L. (2008). The European Union's emission trading system in perspective reports. The Pew Center on Global Climate Change.

[19] Ellis, J., and Tirpak, D. (2006). Linking GHG Emission Trading System and Markets. OECD, COM/ENV/EPOC/IEA/SLT (6). 
[20] EPA (Environmental Protection Agency). (2007). Inventory of US Greenhouse Gas emissions and sinks: 1990-2005. US Environmental Protection Agency, Washington, DC.

[21] Eriksen, S., Aldunce, P., and Bahinipati, S. et al. (2011). When not every response to climate change is a good one: Identifying principles for sustainable adaptation. Climate and Development 3(1): pp 7-20.

[22] Fu, S. J., and Ren, Y. L. (2011). A motivating mitigation mechanism for generators on condition of coordinated regulation of emission and electricity market. Electrical Power and Energy Systems 33(5): pp 1151-1160.

[23] Gillenwater, M. (2008). Redefining RECs-part 1: Untangling attributes and offsets. Energy Policy 36(2): pp 2109-2119.

[24] Goett, A. A., and Hudson, K. (2000). Customers' choice among retail energy suppliers: Willing-to-pay for service attributes. Energy Journal 35(7): pp 1-21.

[25] IPCC (Intergovernmental Panel on Climate Change). (2007). Climate change 2007: Synthesis report. The Working Group contributions to the Fourth Assessment Report. Cambridge University Press, Cambridge, UK.

[26] Klepper, G., and Peterson, S. (2006). Emissions trading, CDM, JI, and more: The climate strategy of the EU. Energy Journal 27(2): pp 1-26.

[27] Kockar, I., Conejo, A. J., and McDonald, J. R. (2009). Influence of the emissions trading scheme on generation scheduling. Electrical Power and Energy Systems 31(8): pp 465-473.

[28] Liliya, C., and Gulli, F. (2008). Marginal $\mathrm{CO}_{2}$ cost pass-through under imperfect competition in power markets. Ecological Economics 8(4): pp 408-421.

[29] Menges, R. (2003). Supporting renewable energy on liberalized markets: green electricity between additionality and consumer sovereignty. Energy Policy 31(7): pp 583-596.

[30] MIT (Massachusetts Institute of Technology). (2009). Retrofitting of Coal-fired power plants for $\mathrm{CO}_{2}$ emissions reductions. Energy Initiative Symposium I.

[31] Morthorst, P. E. (2001). Interactions of a tradable green certificate market with a tradable permits market. Energy Policy 29(5): pp 345-353.

[32] Newcomer, A., Blumsack, S., Apt, L., Lave, B., and Morgan, M. G. (2008). Electricity load and carbon dioxide emissions: effects of a carbon price in the short term. Proceedings of the 41st Hawaii International Conference on System Sciences 5(2): pp 49-52.
[33] Nielson, L. (2008). The European emissions trading system-lessons for Australia. Research Paper, No.3, 2007-08, ISSN 1834-9854.

[34] Nielsen, L., and Jeppesen, T. (2003). Tradable green certificates in selected European countries-overview and assessment. Energy Policy 31(1): pp 3-14.

[35] Paterson, M. (2012). Who and what are carbon markets for? Politics and the development of climate policy. Climate Policy 12(3): pp 82-97.

[36] Perkins, R. (2005). Electricity sector restructuring in India: An environmentally beneficial policy. Energy Policy 33(3): pp 439-440.

[37] PointCarbon. (2004). Special issues - what determines the price of carbon. Carbon Market Analyst 6(2): pp 13-24.

[38] Sijm, J., Neuhoff, K., and Chen, Y. (2006). $\mathrm{CO}_{2}$ cost pass-through and windfall profits in the power sector. Climate Policy 34(6): pp 49-72.

[39] SÖderholm, P., and StrÖmberg, L. (2003). A utility-eye view on the $\mathrm{CO}_{2}$ compliance-decision process in the European power-sector. Applied Energy 75(5): pp 183-192.

[40] Sorrell, S., and Sijm, J. (2003). Carbon trading in the policy mix. Oxford Review of Economic Policy 19(3): pp 420-437.

[41] Stankeviciute, L., Kitous, A. and Criqui, P. (2008). The fundamentals of the future international emissions trading system. Energy Policy 38(2): pp 4272-4288.

[42] Sterk. (2005). Ready to link up? The EU and the international carbon market. Carbon Market Europe 28(5): pp 19-32.

[43] Stern, N. (2007). The economics of climate change: The Stern Review. Cambridge: Cambridge University Press.

[44] Tideman, T. N., and Plassmann, F. (2007). A pricing mechanism for $\mathrm{CO}_{2}$ emissions that incorporates future revisions of estimates of the cost of today's emissions. Journal of Economic Literature 57(9): pp 1-12.

[45] Verhaegen, K., Meeus, L., and Belmans, R. (2009). Towards an international tradable green certificate system - the challenging example of Belgium. Renewable and Sustainable Energy Reviews 13(2): pp 208-215.

[46] Voorspools, K., and D'haeseleer, W. (2006). Modelling of electricity generation of large interconnected power systems: How can a $\mathrm{CO}_{2}$ tax influence the European generation mix. Energy Conversion and Management 47(6): pp 1338-1358. 